University of Nebraska - Lincoln

DigitalCommons@University of Nebraska - Lincoln

January 1999

\title{
Structural domain growth of strained gadolinium on Mo(112)
}

C. Waldfried

University of Nebraska-Lincoln

Peter A. Dowben

University of Nebraska-Lincoln, pdowben@unl.edu

O. Zeybek

Surface Science Research Center, University of Liverpool, Liverpool L69-3BX, UK

T. Bertrams

University of Liverpool

S. D. Barrett

University of Liverpool

Follow this and additional works at: https://digitalcommons.unl.edu/physicsdowben

Part of the Physics Commons

Waldfried, C.; Dowben, Peter A.; Zeybek, O.; Bertrams, T.; and Barrett, S. D., "Structural domain growth of strained gadolinium on Mo(112)" (1999). Peter Dowben Publications. 177.

https://digitalcommons.unl.edu/physicsdowben/177

This Article is brought to you for free and open access by the Research Papers in Physics and Astronomy at DigitalCommons@University of Nebraska - Lincoln. It has been accepted for inclusion in Peter Dowben Publications by an authorized administrator of DigitalCommons@University of Nebraska - Lincoln. 


\title{
Letter
}

\section{Structural domain growth of strained gadolinium on Mo(112)}

\author{
C. Waldfried ${ }^{\mathrm{a}}$, P. A. Dowben ${ }^{\mathrm{a},{ }^{*}}$, O. Zeybek ${ }^{\mathrm{b}}$, T. Bertrams ${ }^{\mathrm{b}}$ and S. D. Barrett ${ }^{\mathrm{c}}$
}

\author{
${ }^{a}$ Department of Physics and Astronomy and the Center for Materials Research and Analysis, University of Nebraska, \\ Lincoln, NE 68588-0111, USA \\ b Surface Science Research Center, University of Liverpool, Liverpool L69-3BX, UK \\ ${ }^{c}$ Surface Science Research Center and Department of Physics, University of Liverpool, Liverpool L69-3BX, UK \\ * Corresponding author. Fax:+1-402-4722879; email: pdowben@unlinfo.unl.edu
}

\begin{abstract}
The growth mode of domains of the hexagonal lattice of strained gadolinium deposited on Mo(112) has been investigated with low-energy electron diffraction (LEED) and scanning tunneling microscopy (STM). The molybdenum substrate corrugations and the expansive strain within the gadolinium films dominate the growth of the thin Gd films, which is characterized by a preferential domain growth direction of the hexagonal Gd crystal structure, unlike the more uniform, epitaxial growth of 'unstrained' gadolinium, grown on W(110).
\end{abstract}

Keywords: Low energy electron diffraction, Scanning tunneling microscopy, Thin film growth, Gadolinium

\section{Introduction}

The crystalline structure and domain growth mode of thin metal films can have significant influences on the electronic and magnetic structure $[1,2,3,4]$. Recently, we have studied the altered magnetic [5, 6 and 7], and electronic $[5,8,9,10$, 11], behavior of strained thin films of gadolinium that were obtained by growing Gd on a corrugated $\mathrm{Mo}(112)$ substrate, as opposed to W(110) [12], which supports a more 'unstrained' $\mathrm{Gd}(0001)$ films. For a complete understanding of the strain induced modified electronic band structure and magnetic behavior, structural analysis is essential. This brief report describes the unique domain growth mode of thin films of $\mathrm{Gd}$ grown on $\mathrm{Mo}(112)$, as determined by low energy electron diffraction (LEED) and scanning tunneling microscopy (STM).

\section{Experimental details}

The STM experiments were carried out with an Omicron room temperature UHV STM at the Surface Science Research Center in Liverpool, UK. All measurements were performed in the constant current mode at a base pressure of $1.0 \times 10^{-10}$ Torr or better. Thin films of strained gadolinium, approximately 15-50 monolayers thick, were grown at room temperature on a Mo(112) crystal and were contiguously annealed to obtain well ordered films as noted elsewhere [11]. The growth and ordering of the Gd films were monitored by LEED and the cleanliness determined with Auger electron spectroscopy. A detailed thickness dependent LEED, photoemission and inverse photoemission study, that correlates the growth and the electronic structure of strained thin films of gadolinium on $\operatorname{Mo}(112)$ is described elsewhere [11].

\section{Results and discussion}

Figure 1 shows the LEED (left) and STM (right) results for thin strained films of $\mathrm{Gd}$, grown on $\mathrm{Mo}(112)$, of approximately 15 (top) and 50 (center) monolayers (ML) thickness, respectively. The STM images of Figure 1 provide evidence for the substrate induced domain growth mode with a preferential growth direction, that is oriented along the $\operatorname{Mo}(112)$ corrugation direction (the substrate $\langle\underline{111}\rangle$ direction). A schematic of the clean $\mathrm{Mo}(112)$ surface with its orthogonal crystallographic directions is shown in Figure 1f.

The domain growth of the $15 \mathrm{ML}$ Gd film (Figure 1b) is characterized by long narrow stripes, one atomic layer thick, approximately $15 \AA$ wide, and separated by nearly equal distanced spacings (of approximately $25 \AA$ ). This nearly uniaxial growth of the Gd films grown on $\mathrm{Mo}(112)$ is consistent with the streaked LEED pattern of the 15 ML thick Gd films, which is shown in Figure 1a. This type of LEED pattern is indicative of disorder along the $\langle 110\rangle$ direction. 

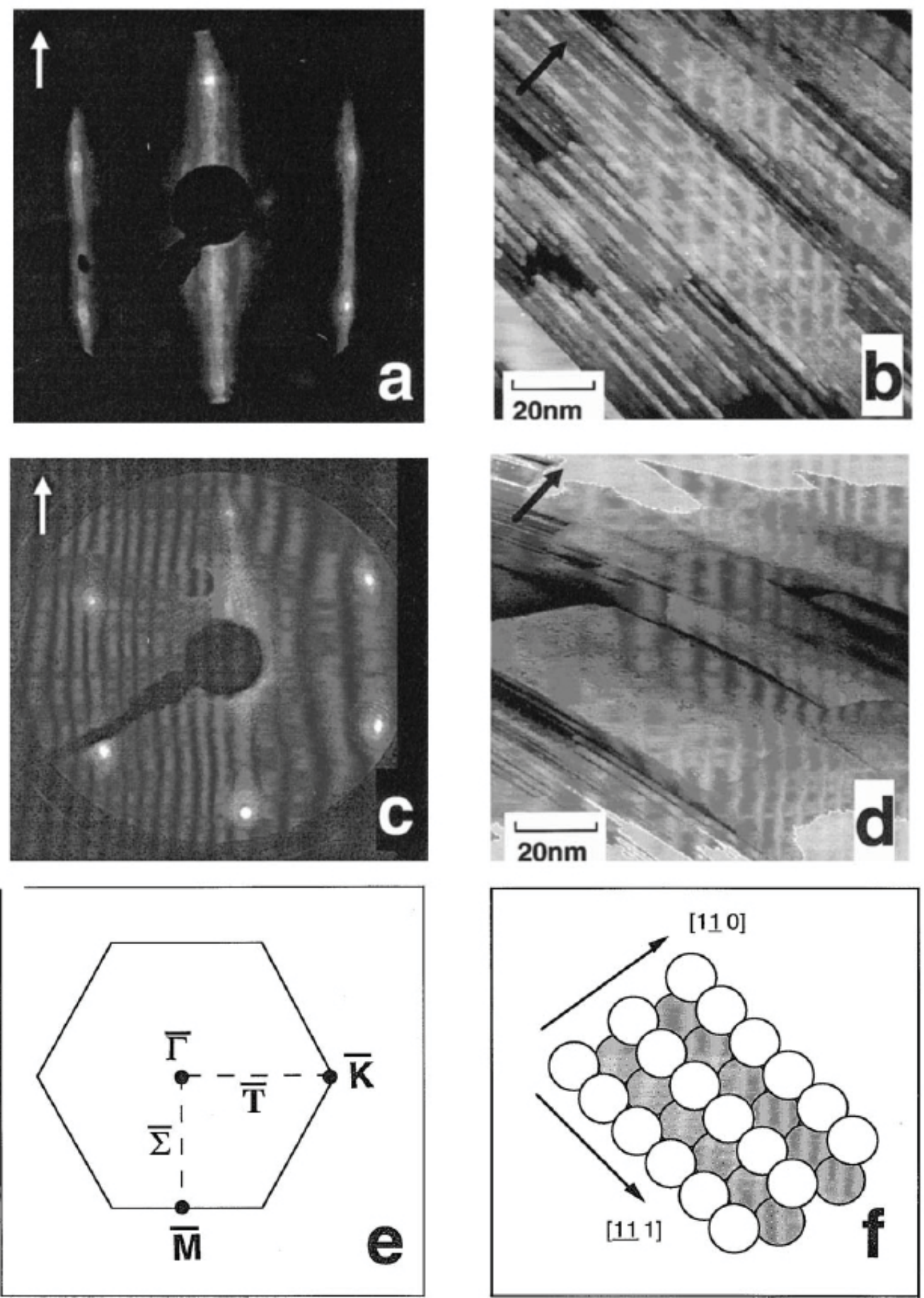

Figure 1. LEED pattern $\left(E_{\mathrm{i}}=54.2 \mathrm{eV}\right)(\mathrm{a}, \mathrm{c})$ and STM images $(1000 \times 1000 \AA)(\mathrm{b}, \mathrm{d})$ for thin strained films of Gd, grown on Mo(112), of approximately $15 \mathrm{ML}$ (top) and $50 \mathrm{ML}$ (center) thickness, respectively. The arrows indicate the Mo(112) substrate $\langle 1 \underline{10}\rangle$ crystallographic direction. Panel (e) shows the hexagonal Brillouin zone of gadolinium. The schematic surface structure of the Mo(112) substrate is displayed in panel (f). The Mo-Mo atomic distances are $4.45 \AA$ along the $\langle 1 \underline{10}\rangle$ direction and $2.73 \AA$ along the $\langle 1 \underline{10}\rangle$ direction. The gray scale represents 6 $\AA$ from black to white.

The hexagonal LEED diffraction spots that are superimposed on to the streaks (Figure 1a) are in reasonable agreement with the dimensions of the hexagonal unit cell $\left(a_{\mathrm{Gd}} \approx 3.64 \AA\right)$. This indicates the persistence of the naturally hexagonal crystalline structure of the Gd films and the tendency for the $c$-axis orientation along the surface normal, as has been noted before [13]. The hexagonal Brillouin zone of Gd is shown in Figure 1e. Careful LEED analysis [11] of the 
Gd films grown on $\operatorname{Mo}(112)$ determined the hexagonal unit cell to be uniformly expanded by approximately $4 \%$ as compared to $3.64 \AA$ basal face lattice constant of 'unstrained' Gd films, grown on $\mathrm{W}(110)$. This amount of strain is also consistent with the band structure and position of the Brillouin zone edge [11].

The nearly equal dimensioned spacings in between the narrow Gd domains are consistent with an expanded lattice. An expansive strain results in a repulsive energy that is minimized by an arrangement of equal distanced separation in between the repulsive objects [14 and 15]. Such repulsive strain energy effecting the surface lattice is commonly seen for steps $[15,16$, and 17], surface dislocations [17 and 18], and facets [15 and 16].

The STM images of the approximately 50 ML thick Gd films are characterized by much wider, more 'rectangular' shaped domains. The domains are approximately 100-500 wide, many $100 \AA$ long, and one atomic layer thick. We note that the termination of the short sides of these domains form angles of $60^{\circ}$ or $120^{\circ}$ with respect to the long sides, rather than $90^{\circ}$, indicative of the hexagonal crystalline ordering within these domains. The larger, more uniform domains of the thicker Gd films are consistent with the LEED pattern of the $50 \mathrm{ML}$ thick film, which is shown in Figure 1c. The streaks are significantly weaker as compared to the LEED image of the thinner Gd films ( Figure 1a) and the hexagonal diffraction spots are sharper and more prominent. The LEED pattern is characteristic of larger domain sizes and the hexagonal surface lattice structure, is in agreement with the STM results.

The domain growth mode of strained Gd grown on $\mathrm{Mo}(112)$ is very different from the growth mode of the "unstrained' Gd grown on W(110), which is characterized by a more uniform domain formation with no preferential growth direction [1, 19, 20, 21, 22 and 23]. The differences in the lattice domain growth modes have significant effects on the electronic and magnetic structure of the thin Gd films [11]. For the thinner strained $\mathrm{Gd}$ films $(d \approx 15 \mathrm{ML})$ that are grown on Mo(112), the long but very narrow domains result in a anisotropic band dispersion of both the bulk and the surface electronic bands [11]. Along the $\langle 1 \underline{10}\rangle$ substrate direction there is negligible dispersion in the strained Gd films which is in contrast to the Gd films grown on W(110). In the perpendicular direction (along $\langle\underline{11} 1\rangle$ of the substrate) the bands of the strained Gd films disperse, but different than those of the "unstrained' $\mathrm{Gd}$ [11]. For the thicker strained Gd films $(d \approx 50$ ML), the significantly wider and larger domains result in dispersion along both $\mathrm{Mo}(112)$ substrate high symmetry directions, $\langle\underline{111}\rangle$ and $\langle 110\rangle$.

\section{Summary}

While LEED indicates that the thinner films grown on Mo(112) are defective and/or disordered, and the thicker films of strained $\mathrm{Gd}(0001)$ are far more crystalline, STM results remain essential for understanding of the growth morphology. With STM, it is clear that the growth mode has a substantial influence on the disorder apparent in LEED. The largely uniaxial disorder, of the hexagonal lattice in the thinner films, is a consequence of the domain structure and shape. We have shown the influence of the Mo(112) substrate on the domain growth of thin films of Gd is most pronounced in the thinner films and that the thicker films, when annealed, have a flatter profile with fewer step defects and dislocations at the surface. The Gd films are expansively strained by approximately $4 \%$ and have a preferential growth orientation along the $\langle 111\rangle$ direction of the $\operatorname{Mo}(112)$ substrate which is persistent in films that were estimated to be $50 \mathrm{ML}$ thick. The thickness dependent domain structure determined by a combination of STM and LEED, and is seen to be different than the domain growth of the conventional Gd(0001) grown on $\mathrm{W}(110)$. The unique growth mode of the strained Gd films grown on Mo(112) may be correlated to the altered band structure [11] and possibly to the distinct magnetic behavior, [5 and 6].

\section{Acknowledgements}

This work was funded by the NSF through grant DMR-9496131, 98-02126.

\section{References}

1. E. D. Tober, R.X. Ynzunza, C. Westphal and C. S. Fadley. Phys. Rev. B 53 (1996), p. 5444.

2. O. Rader, C. Carbone, W. Clemens, E. Vescovo, W. Blügel and W. Gudat. Surf. Sci. 287 (1993), p. 736.

3. J. Lee, G. Lauhoff, M. Tselepi et al.. Phys. Rev. B 55 (1997), p. 15103.

4. P. Sonntag, P. Bödeker, T. Thurston and H. Zabel. Phys. Rev. B 52 (1995), p. 7363.

5. C. Waldfried, D. Welipitiya, T. McAvoy, T. Komesu, P. A. Dowben, E. Vescovo, Phys. Rev. B, submitted.

6. C. Waldfried, T. McAvoy, D. Welipitiya, E. Vescovo, P. A. Dowben, Europhys. Lett., (1998) in press..

7. C. Waldfried, D. Welipitiya, T. McAvoy, E. Vescovo, P. A. Dowben, J. Appl. Phys., (1998) in press..

8. C. Waldfried, D. N. Mcllroy and P. A. Dowben. Phys. Rev. B 54 (1996), p. 16460.

9. C. Waldfried, D. N. McIlroy and P. A. Dowben. Phys. Rev. B 56 (1997), p. 9973.

10. C. Waldfried, D. N. McIlroy, D. Welipitiya, T. McAvoy, E. Vescovo, P. A. Dowben, J. Appl. Phys., (1998) in press..

11. C. Waldfried, D. N. Mcllroy and P. A. Dowben. J. Phys. Condens. Matter 9 (1997), p. 10615.

12. D. Li, J. Pearson, S. D. Bader, D. N. McIlroy, C. Waldfried and P. A. Dowben. Phys. Rev. B 51 (1995), p. 13895. 
13. P. A. Dowben, D. LaGraffe, D. Li, A. Miller, L. Zhang, L. Dottl and M. Onellion. Phys. Rev. B 43 (1991), p. 3171.

14. W.K. Burton and N. Cabrera. Disc. Faraday Soc. 5 (1949), p. 33.

15. E. D. Williams. Surf. Sci. 299 (1994), p. 502.

16. E. D. Williams, R. J. Phaneauf, J. Wei and N. C. Bartelt. T.L. Einstein Surf. Sci. 294 (1993), p. 219.

17. R. C. Nelson, T. L. Einstein, S. V. Khare and P. J. Raus. Surf. Sci. 295 (1993), p. 462.

18. R. J. Phaneauf, N. C. Bartelt, E. D. Williams, W. Swiech and E. Bauer. Phys. Rev. Lett. 71 (1993), p. 2284.
19. R. Pascal, C. Zarnitz, M. Bode and R. Wiesendanger. Surf. Sci. 385 (1997), p. L990.

20. D. Weller, S. F. Alvarado, W. Gudat, K. Schroder and M. Campagna. Phys. Rev. Lett. 54 (1985), p. 1555.

21. D. Weller and S. F. Alvarado. J. Appl. Phys. 59 (1986), p. 2908.

22. J. Kolaczkiewicz and E. Bauer. Surf. Sci. 175 (1986), p. 487.

23. R. G. White, M. H. Lee, N. P. Tucker, S. D. Barrett and P. W. Murray. Phys. Rev. B 56 (1997), p. R10071. 